\title{
Actor-Network Theory as a Framework to Analyse Technology Acceptance Model's External Variables: The Case of Autonomous Vehicles
}

\author{
Patrice Seuwou ${ }^{1,2(\bowtie)}$, Ebad Banissi ${ }^{1}$, George Ubakanma ${ }^{1}$, \\ Mhd Saeed Sharif ${ }^{3}$, and Ann Healey ${ }^{2}$ \\ ${ }^{1}$ Division of Computing and Informatics, School of Engineering, \\ London South Bank University, London, UK \\ \{seuwoup, banisse, george.ubakanma\}@lsbu.ac.uk \\ ${ }^{2}$ Department of Digital Innovation and Creative Enterprise, \\ GSM London, London, UK \\ \{patrice. seuwou, ann.healey\}@gsmlondon.ac.uk \\ 3 Department of Electronic and Computer Engineering, \\ Brunel University London, Uxbridge, UK \\ mhd. sharif@brunel.ac.uk
}

\begin{abstract}
The main factor for growth in a globalised and highly competitive world is to have an innovative and continuous improvement for the new technologies; however, it is difficult to guarantee the success of such factor without considering the human nature of the people. The Unified Theory of Acceptance and Use of Technology (UTAUT2) is a model that has been used for years to help us understand the drivers of acceptance of new information technologies by its users. This paper presents the Actor-Network Theory (ANT) as a framework to analyse external variables influencing technology acceptance. We have identified a new construct and moderating factor enabling the extension of the UTAUT2. The scenario used to conduct our investigation is the Autonomous Vehicle (AV) which is a disruptive technology and may prove to be the next big evolution in personal transportation. The study was conducted using an anonymous survey, over 410 responses so far, and numerous interviews with experts in the field of sociology, psychology and computer science in order to refine the proposed model. Our research findings reveal not only the usefulness of ANT in developing an understanding the human and non-human actants playing a role in consumer's behavioural intention of using AV, but ANT also helps us to argue that culture is a direct determinant of behavioural intention and social class is a very important moderating aspect.
\end{abstract}

Keywords: Technology acceptance model $\cdot$ Unified theory of acceptance and use of technology $\cdot$ Actor-Network theory $\cdot$ Autonomous vehicles $\cdot$ Security 


\section{Introduction}

The development of information technologies has resulted in an ever-increasing advancement of products which continues to challenge and cater to the attitudes of consumers. Understanding individual acceptance and use of information technology is one of the most mature streams of information systems research [1]. Various theoretical models, primarily developed from theories in psychology and sociology have been devised to predict adoption and use of technology. The case used for our investigation is autonomous vehicles as a disruptive technology examined using the Actor-Network Theory (ANT) as an analytical framework to explore the human and non-human actants influencing the acceptance of self-driving cars. Autonomous vehicles have existed as prototypes and demonstration vehicles since the 1970s. These vehicles can drive themselves without human supervision or input, but for the moment, a fully autonomous vehicle capable of completing an entire journey on public roads without any human input is still some way from being realized [2]. Reliability, safety, cost, appearance, trust, cyber liability, personal freedom, technology dependence, liability, legislation and social acceptance are only a few of the legitimate concerns the public currently have with regards to autonomous vehicles [3, 4]. Certainly the autonomous vehicle is a disruptive technology. Not all technologies predicted by popular media are immediately welcomed into society, and autonomous cars are one such technology. As typical with much advancement, some people will oppose them and the changes that they will bring. There are both human and non-human factors influencing the introduction of autonomous vehicles in the market. Our aim, in this study, is to identify other constructs initially neglected by previous models and theories but that could play a major role on people's behavioural intention to adopt self-driving cars. Since its original publication, UTAUT has served as a baseline model and has been applied to the study of a variety of technologies in both organisational and non-organisational settings. There have been many applications and replications of the entire model or part of the model in various settings that have contributed to fortifying its generalizability. Building on the past extensions to UTAUT, the objective of our work is to use the Actor-network theory as an analytical framework while paying particular attention to the influence of culture and social class on consumers' behavioural intention of using technology.

\section{Autonomous Vehicles as a Disruptive Technology}

Despite our desire to maintain control over our lives, the bulk of what we do with our lives has been coordinated and adapted by and to the technology that surrounds us $[5,6]$. It should come as no surprise that when existing technology evolves or old technology is made obsolete, the phase where new technology enters our lives could be seen as being disruptive. This disruption occurs when the technology, which is introduced effects the social arrangements around which we build our lives [7, 8]. The term "disruptive technology" as coined by Christensen [9] refers to a new technology having lower cost and performance measured by traditional criteria, but having higher ancillary performance. Christensen finds that disruptive technologies may enter and 
expand emerging market niches, improving with time and ultimately attacking established products in their traditional markets. There are sustaining technologies, which enhance the characteristics of existing products or services and, most of the time, mainstream customers and the market appreciate and adopt these technologies rapidly. Disruptive technologies are radically different and disrupt or challenge the current way of doing things. Products based on such technologies underperform in the current market-place at first, but a few customers value them. However, eventually the innovation becomes so compelling that everyone rapidly abandons their current way of doing things and flocks to what is new.

The transportation business is a $\$ 4$ trillion industry globally [10]. This industry is inextricably linked with energy. Certainly, the internal combustion engine automobile will soon be disrupted, an event which will, in turn send disruptive shockwaves through the oil industry. The first wave of disruption of the century old automotive industry is well underway with electric vehicles. The second disruptive wave, the self-driving car, will hit before the first wave is finished crashing. Transportation will never be the same again. Autonomous Vehicles (AVs) will be here much sooner than most people expect and will lead to major changes in transportation, our cities and society as a whole. Most car manufacturers and some technology companies are actively developing and testing AVs. Some preliminary versions of AVs are already commercially available. The new auto technology will bring disruption with massive opportunities. Indeed, near autonomous cars followed by driverless vehicles (smart cars) will transform our commute to work and much more over the next two decades. Electric and hybrid cars are set to become a large part of our fleet, changing the demand for motoring and disrupting our pay-as-you-go revenue base. Most of these vehicles will be powered by electric power. Furthermore, we will expect a much safer and easier commute with fewer fatalities, dramatic accident reductions, and reduced congestion. On the other hand, car-based technologies hold the promise of reducing the billions of pounds we spend on roads by improving how we use them and by saving lives. Public transport will also be challenged as car journeys become cheaper, safer and easier to make and without environmental emissions, lower congestion. Some industries will have to change their business model, reinvent themselves or disappear altogether. When designing infrastructure policies, there is a tendency to assume that the future is simply an extension of the past. AVs are a truly disruptive technology and we cannot forecast the future by simply extrapolating from the past. All of the above issues will change the forecasts for standard infrastructure and major infrastructure projects.

\section{Autonomous Vehicles Security and Safety Challenges}

With more than $90 \%$ of accidents each year caused by driver error, one of the major motivations for developing AVs is the potential impact on vehicle safety. Current technologies utilize sensor arrays (LIDAR is used to a large extent) to create a 3 -dimensional model of the space all around the car [56] It is estimated that over 90\% of all accidents are due to human error or bad driving behaviour, whether it be reckless driving or driving while intoxicated [57] AV is just an extension of existing technologies such as Vehicle-to-vehicle (V2 V) and Vehicle-to-Infrastructure (V2I) 
allowing communication between vehicle and road side base stations. One goal of developing AV is to render these types of accidents a thing of the past. In spite of the various benefits of increased vehicle automation, some foreseeable challenges may include liability for damage, resistance of individuals to forfeit control of their cars, software reliability. AVs will have a high level of computer technology on board and may be connected to the internet, other vehicles and possibly their surroundings. As a result cyber security issues need to be carefully considered as car's computer or communication system between cars could potentially be compromised. They will also be ethical issues surrounding the privacy and use of data and testing, certification and licensing. Other challenges will include implementation of a legal framework and establishment of government regulations for self-driving cars, reliance on autonomous drive will produce less experienced drivers when manual control is needed. The loss of driver-related jobs with reduced demand for parking services and for accident related services assuming increased vehicle safety. There is also going to be a reduction in jobs relating to car insurance and traffic police. However, because the transition to driverless cars is likely to be spread over many years, the loss of jobs is likely to be gradual and manageable.

\section{Theoretical Background}

Throughout the years, there have been several theoretical models, primarily developed from theories in psychology and sociology, employed to explain technology acceptance and use $[1,11,12]$. The Unified Theory of Acceptance and Use of Technology (UTAUT) has distilled the critical factors and contingencies related to the prediction of behavioural intention to use a technology primarily in organisation contexts. UTAUT resulted from the synthesis of existing theories/models of technology use [1]. It was developed on the basis of integrating the dominant constructs of eight prior prevailing models that range from human behaviour, to computer science.

The eight models are: Theory of Reasoned Action [13], Technology Acceptance Model [14], Motivational Model [15], Theory of Planned Behavior [16], Combined TAM and TPB [17, 18], Model of PC Utilisation (MPCU) [19], Innovation Diffusion Theory [20], and Social Cognitive Theory [21]. Since the original publication, UTAUT has served as a baseline model and has been applied to the study of a variety of technologies in both organisational and non-organisational settings [22]. The work in [23] found that overall the UTAUT constructs were a useful starting point in studying scholarly behavioural intention and use of social media as well as various other technologies, but further research is required to better understand the factors influencing human behavioural intention to accept and use technology. The scenario used for our investigation is Autonomous Vehicles (AV) as a disruptive technology. Undeniably, for years, almost all commercial aircraft have had the ability to operate on autopilot. On-board computers can manage most aspects of flying, including even aspects of take-off and landing. This technology displays numerous benefits to the aviation industry and has been accepted by consumers. Today, similar technologies are being introduced in the car manufacturing industry as research shows that traffic accidents are a major source of disability and mortality worldwide. Every year, more 
than 1.2 million people die and up to 50 million people are injured because of road accidents [24]. In 2005-2007, the DARPA Grand Challenge and Urban Challenge provided researchers with a practical scenario in which to test the latest sensors, computer technologies and artificial intelligence algorithms [3]. Autonomous or highly aware vehicles have the potential to reduce these numbers dramatically and save many lives across the world. Arrival of new technologies always brings new challenges and problems. Normally, there are human and non-human factors influencing the deployment of autonomous vehicles in the market. Therefore, the way the public perceives these self-driving cars will directly affect the way they will be introduced to the market and how quickly they will be seen on the streets. Certainly to accept the concept of vehicles on the roads without a human at the controls, the car users must have faith that the systems are safe. Surely, the public's willingness to accept this technology will determine how car manufacturers develop and market them.

This research attempts to build upon and extend the Unified Theory of Acceptance and Use of Technology (UTAUT2) and to enhance our understanding of the factors that influence people behavioural intention of acceptance and use of technology [12]. A number of studies have identified that people don't like changes as most people are reluctant to alter their habits [25]. Many authors believe that customer acceptance is likely to be the biggest obstacle to autonomous vehicle penetration [2, 26, 27]. At first, many consumers may be reluctant to put their lives in the hands of a robot. Recent studies and surveys have shown a split in opinion as to whether people would like autonomous capability to be available in their vehicles or not. User acceptance is a key ingredient to the successful adoption of autonomous vehicles. Empirical evidence shows that automation has a substantial influence on human behaviour. With automation, the role of the human driver changes substantially. Indeed this is a very important 'human factors' issue and throughout the years, many processes within cars have become automated including cruise control and anti-lock brakes amongst others. However, the transition from humans as drivers to humans as merely passengers in a car that drives itself is a major one. People generally have emotional connections with their vehicles, therefore, are drivers actually willing to give up direct control over their vehicle and under what conditions? If automation of vehicles is not accepted by the users and users refrain from using the technology, the impact of automation on traffic flow efficiency, traffic safety and energy efficiency is mitigated. It is, however, not yet clear to what extent users accept automation and what the determinants of consumer acceptance of automation are [28].

\section{Conceptual Model}

\subsection{Methodology}

To gain a better understanding of the current situation, Actor-network theory (ANT), also known as the sociology of translation is the tool adopted in this research for exploring collective sociotechnical processes while analysing the human and non-human actants playing a role in this complex network referred to as assemblage. ANT approach emerged within the sociological research of science and technology, 
having its roots in French philosophy and semiotics. Since then, ANT has spread into various contexts of sociological inquiry [29, 30,39]. It is seen as a socio-philosophical approach that seeks to understand complex social circumstances by paying attention to relational factors referred to as associations [31,32]. This tool will be supplemented by interviews with psychologists, sociologist, computer scientists from various UK universities and a survey as part of the research strategy, drawing on multiple sources of data in order to collect rich evidence and explanations of phenomenon on the issue of what influences individuals to accept or reject autonomous vehicles as a disruptive technology.

\subsection{Overview of the Actor Network Theory (ANT)}

ANT is a Theory developed in the 1980s from the work of Bruno Latour, Michel Callon and John Law in order to study the relationship between both human and non-human objects within a given scenario. The ANT approach emerged within the sociological research of science and technology, having its roots in French philosophy and semiotics. Actor network theory highlights the nature of relations and theorizes that they can be both semiotic (meaning making) and material. Since then, ANT has spread into various contexts of sociological inquiry [29,30]. It is seen as a socio-philosophical approach that seeks to understand complex social circumstances by paying attention to relational factors referred to as associations [31,32]. The [33] argues that the "social is not the glue which holds society together; rather it is what is glued together by many other types of connectors. It is not a specific realm...but only...a very peculiar movement of re-association and reassembling...a trail of associations between heterogeneous elements". [34] Says 'Social scientists have transformed the world in various ways; the point, however, is to interpret it'.

Traditional methods advocate that to examine any given scenario, a framework must first be applied, in order to instruct the observation of the participants, however, Latour and Woolgar's work, at the Salk Institute in California, was conducted in the absence of prior assumptions of scientific methods, approaching their research as if they were anthropologists, observing some unknown phenomena. With the deliberate absence of a hypothesis, focus was centred on the observer's experience as being the only true source for understanding, rather than utilising pre-existing concepts of what should be [35, 41].

This anthropological approach introduced the concept of reflexivity, the idea that both the observer and observed are engaged in comparable activities [36-38, 40]. By the 1980's, due to the work of Michel Callon, Bruno Latour and John Law at the Centre de Sociologie de l'Innovation, the architecture of actor-network theory (ANT) had emerged.

ANT is problematic to define, in that it is more easily understood by application rather than delineation or explanation. This is an attempt to situate it as a starting point for analysis, in order to hurdle the academic predicament that has been established by some of the contrasting approaches to social science.

How legitimate is it, to discuss social classes, and hypothesise certainties about these classes, when inferred from observations based on just a few? Can a sociological 
account of scientific and technical controversies have any validity, if it is just as susceptible to ideas of ambiguity and uncertainty as the natural sciences? [42].

For the ANT practitioner, it is important to assume nothing, in order to overcome this problem of generality [44]. In the absence of assumptions, understanding is not obscured by prior perspectives. [34] proposed a need to investigate more meticulously what is meant by the notion of the sciences, redefining sociology as a 'tracing of associations' since for the ANT theorist, the starting point is neither society nor the social, as for them, neither are fixed. Thus, the social and natural sciences take on the same roles in an analysis as they are both assumed by the observer to be equally unpredictable [42].

\subsection{Actor-Network Theory as an Analytical Framework}

ANT enables the delineation of a set of actors (the network) that influence, shape or determine an action [30], which facilitates the identification of relationships within and between actors in the same or different networks. It comprises four main components, the first being the actor or the actant, who is not just seen as a "point object" but rather as an association of various factors, themselves forming an actor-network [45]. An actor or actant may be an individual, a group, an idea, a piece of software, a material object, a plant, natural capital or an animal that acts towards something. It may not inevitably be the source of an action but instead may modify and enhance the state of affairs by making a significant difference [34, 43]. The second component relates to the "links" or relationships that exist between the actors, and may include money transfers, verbal or written communication, publications sent to subscribers, friendships, or resource exchange, including information and overlapping memberships of networks. The third element is the "network", which may be an individual, a group, an idea, a physical object, a plant or an animal. It could also be an interactive assembly of entities, or a group or "series of actions" including a number of potential mediators [43]. The fourth component is the action itself [43], and relates to agency, or taking seriously what the actors (human or non-human) have to say. Figure 1 shows a blending the Technology Acceptance Model (TAM) and the Actor-Network Theory (ANT) to create a combined TAM - ANT model.

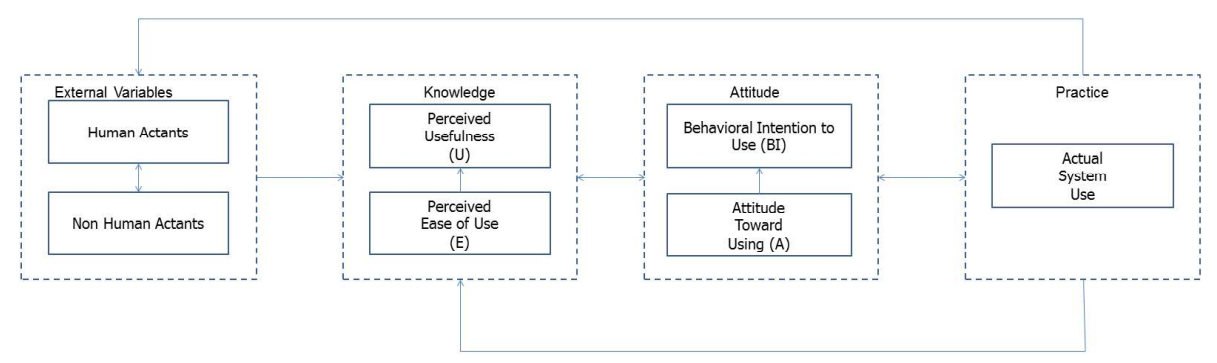

Fig. 1. Combined TAM - ANT model 
According to [47], ANT seeks to examine the tools by which relationships emerge, and how the roles of subjects and objects, and intermediaries, human actors (i.e. people, organizations, and groups) and non-humans (the natural environment, software, and computers) are attributed and stabilized. The point of interest is how these and other categories come into existence via the processes involved in constituting a network. The work in [48] claims that these processes of association and reassembling are at the core of Actor-network Theory. ANT supposes that collective action is made up of a series of human and non-human actors, and a translation carried out through a translator or an interpreter will create various relationships between these heterogeneous actors, which then become networked. The process of translation is a concatenation of successive stages, transformations, and redefinitions of the collective project, through which actors (human and non-human) are mobilized in various ways. [33] argue that the network is "a chain of actions consolidated by mediators... [in which] actors and non-humans are associated with the same project".

The main idea behind ANT is that the collective, needs to be distinguished from a collective or the idea of collectivity [47]. This means that it is the relationships and their divergence that are essential, and not the things themselves [47]. Four important points should be noted about this definition: (1) Networks are always being gathered and re-gathered for specific projects; they are constantly in flux. (2) Networks are interim entities; their existence depends essentially on the action of ongoing relationships. (3) ANT, in contrast to other network theories, ascribes power to non-human actors in the network, such as the natural environment, objects, technologies, software, machines, implements and computers. (4) Contrary to mediators, translators are the dynamic element of networks, which effect the changes that lead towards the recognition of specific projects [33]. ANT is based on three methodological principles [46, 49]. The first principle is "agnosticism", which is the requirement of impartiality regarding the actors involved in the network [50]. ANT compels dispassion and holds that all interpretations should be unbiased $[42,43]$. The second ANT principle is "generalized symmetry", which offers a counterbalance to the principle of agnosticism as it continues the idea of equivalence between human and non-human actors [51]. Symmetry refers to the idea of networks being formed where human and non-human actors have equally important roles [42]. The third principle, "free association", argues that heterogeneous actors can be linked together through a number of conceptual divisions, such as national/international, cultural/natural, or social/natural [52]. The work in [50] argues that ANT looks at the transformation of heterogeneous networks into aligned networks, which can be composed of individuals, groups, organizations, technologies, animals and more. It examines how the networks emerge, who or what is involved, how the networks are maintained, and how networks of actors compete with other networks. Moreover, ANT investigates the mechanics of power through the networks' construction and maintenance (both human and non-human) (Fig. 2) [50].

The application of this body of theory may thus facilitate an examination of the roles of, and the relationships between, structural actants, digital actants, software actants, hardware actants, cultural actants and human actants which lies at the heart of this study (Figs. 3 and 4). 


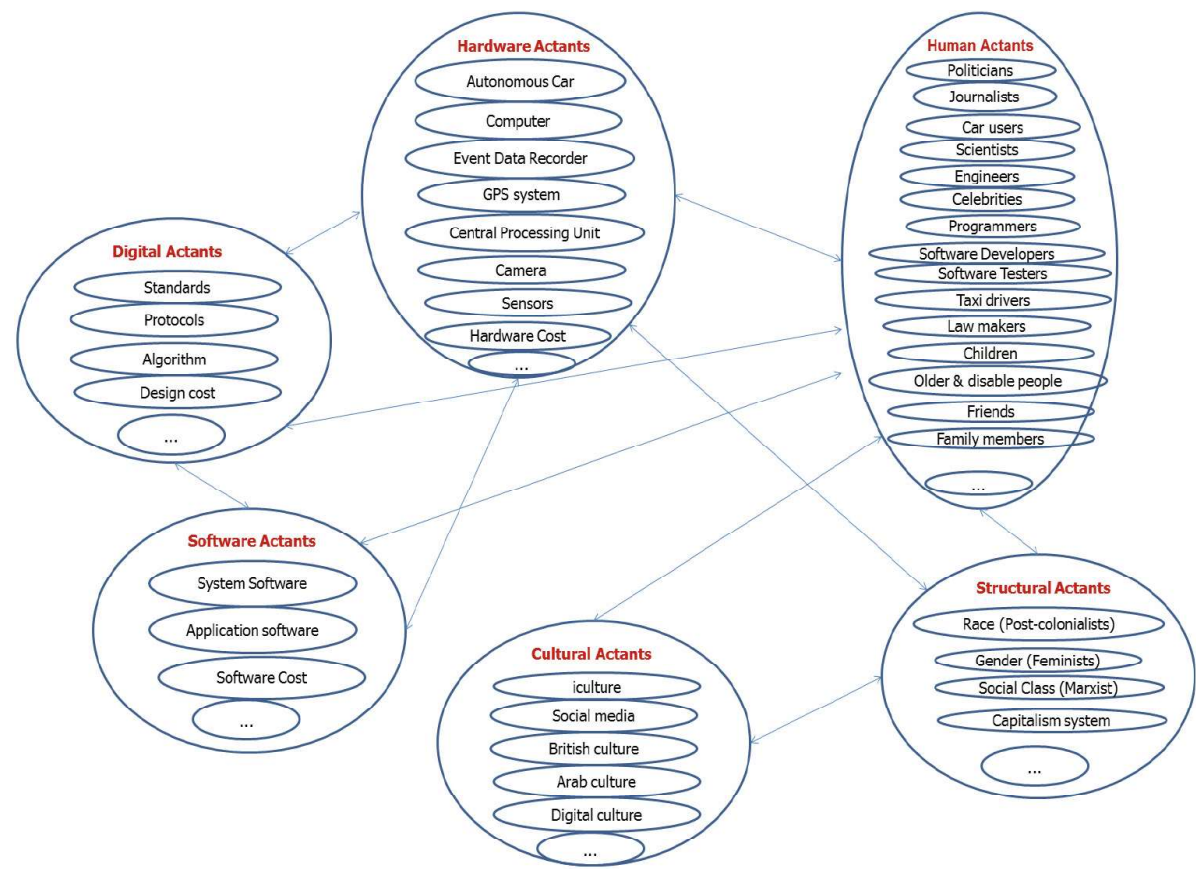

Fig. 2. Connection of actants in an assemblage for autonomous vehicle

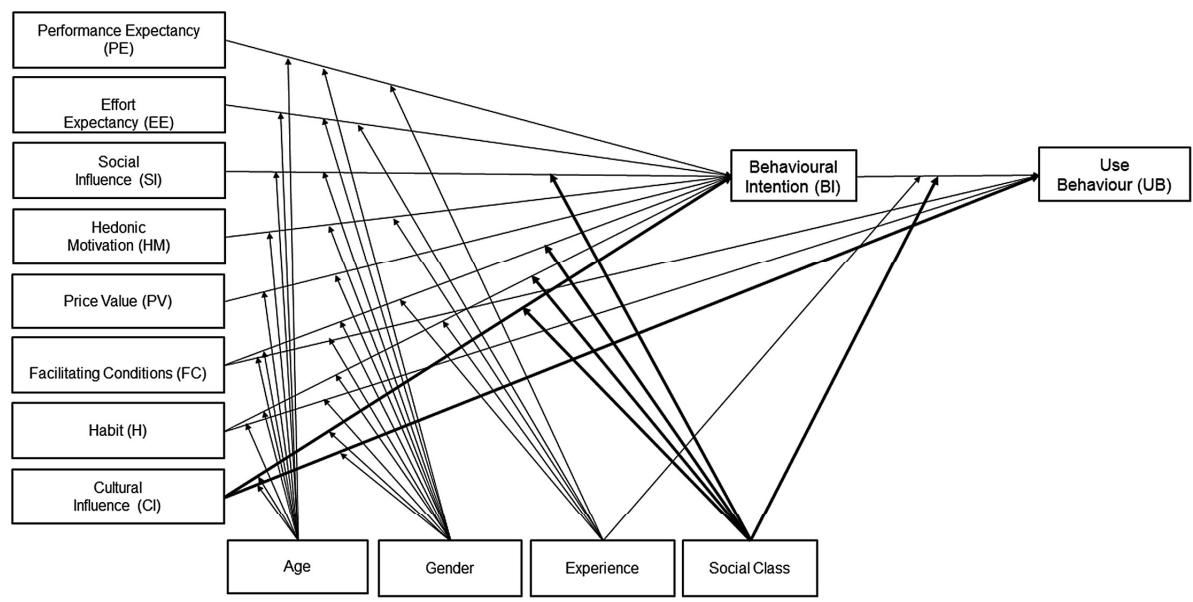

Fig. 3. Proposed research model

Our research framework provides the theoretical basis for explaining how various other important actants have been identified using the Actor-Network Theory which could be used to enhance the existing UTAUT2 Model (Table 1). 


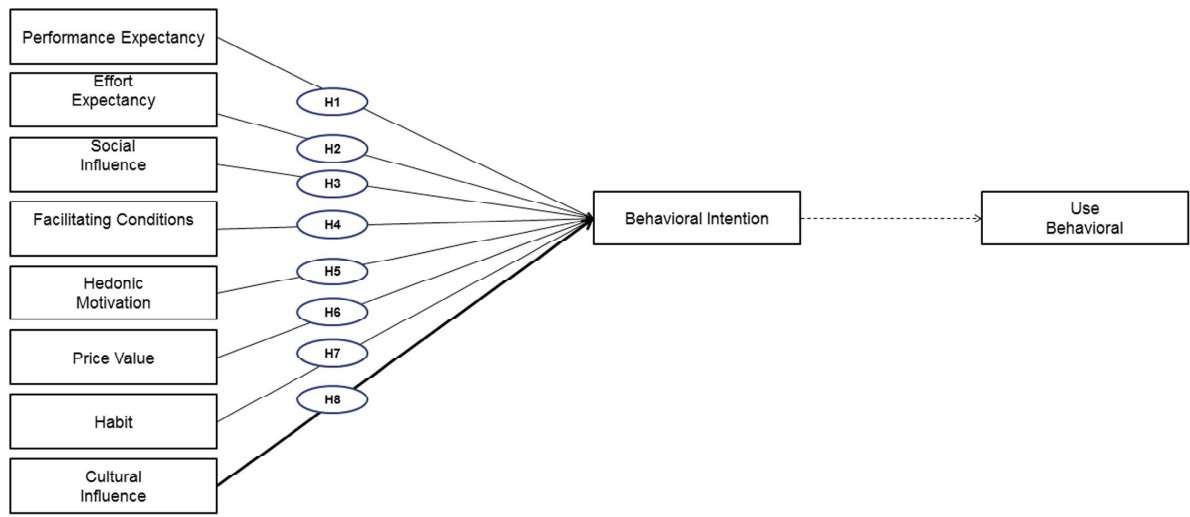

Fig. 4. Consumer acceptance and use of information on technology: extending the unified theory of acceptance and use of technology. Adapted from: [12].

Table 1. A brief description of the research model constructs

\begin{tabular}{l|l}
\hline Determinates/constructs & Description \\
\hline Performance & $\begin{array}{l}\text { Performance expectancy is defined as the degree to which an } \\
\text { individual believes that using autonomous vehicles will help him } \\
\text { or her to attain gains in daily life activities, increase productivity, } \\
\text { decrease possibilities of accidents on the road and makes driving } \\
\text { more secure. PE also takes into consideration security features of } \\
\text { the car; provide some level of satisfaction about trust, and privacy } \\
\text { protection. Gender and age is theorised to play a moderating role. } \\
\text { The influence of performance expectancy on behavioural intention } \\
\text { will be moderated by gender and age, such that the effect will be } \\
\text { stronger for men and in particular for younger men }\end{array}$ \\
\hline
\end{tabular}

Effort Expectancy (EE) Effort Expectancy is defined as the degree of ease associated with the use of autonomous vehicles. The ease is associated with learning how to use autonomous vehicles and how clear and understandable the interaction with the technology is. The influence of effort expectancy on behavioural intention will be moderated by gender and age, experience. We suggest that effort expectancy is more salient for women than for men. The gender differences predicted here could be driven by cognitions related to gender roles. Increased age has been shown to be associated with difficulty in processing complex stimuli and allocating attention to information. Thus we propose that effort expectancy will be most salient for women, particularly those who are older and with relatively little experience with autonomous vehicles. The influence of effort expectancy on behavioural intention will be mo derated by gender, age and experience, such that the effect will be stronger for women, particularly younger women and particularly at early stages of experience 
Table 1. (continued)

\begin{tabular}{|c|c|}
\hline Determinates/constructs & Description \\
\hline Social Influence (SI) & $\begin{array}{l}\text { Social Influence is defined as the degree to which an individual } \\
\text { perceives that important others believe he or she should use the } \\
\text { technology. Social influence occurs when one's emotions, } \\
\text { opinions, or behaviours are affected by others. Social influence } \\
\text { takes many forms and can be seen in conformity, socialisation, } \\
\text { peer pressure obedience, persuasion, sales and marketing, and } \\
\text { review of information. Furthermore, social influence as a direct } \\
\text { determinant of behavioural intend on contains the explicit or } \\
\text { implicit notion that the individual's behaviour is influenced by the } \\
\text { way in which they b eh eve others will view them as a re suit of } \\
\text { having used autonomous vehicles. The impact of social influence } \\
\text { on behavioural intention will be moderated by gender, age and } \\
\text { experience, such that the effect will be stronger far women, } \\
\text { particularly older women, particularly older women in mandatory } \\
\text { stages of experience }\end{array}$ \\
\hline $\begin{array}{l}\text { Hedonic Motivation } \\
\text { (HM) }\end{array}$ & $\begin{array}{l}\text { Hedonic Motivation is defined as the fun or pleasure derived from } \\
\text { using a technology, and it has been shown to play an important } \\
\text { role in. determining technology acceptance and use. Thus the } \\
\text { influence of hedonic motivation on behavioural intention will be } \\
\text { moderated by gender, age and experience }\end{array}$ \\
\hline Price Value (PV) & $\begin{array}{l}\text { The cost and pricing structure may have a significant impact on } \\
\text { consumers' technology use. In marketing research, the monetary } \\
\text { cost price is usually conceptualized together with the quality of } \\
\text { products or services to determine the perceived value of products } \\
\text { or services. We follow these ideas and define price value as } \\
\text { consumers' cognitive tradeoff between the perceived benefits of } \\
\text { the applications and the monetary cost for using them [53]. The } \\
\text { price value is positive when the benefits of using a technology are } \\
\text { perceived to be greater than the monetary cost and such price } \\
\text { value has a positive impact on intention. Thus, price value has } \\
\text { been added as a predictor of behavioural intention to use } \\
\text { autonomous vehicles }\end{array}$ \\
\hline $\begin{array}{l}\text { Facilitating Conditions } \\
\text { (FC) }\end{array}$ & $\begin{array}{l}\text { Facilitating Conditions are defined as the degree to which an } \\
\text { individual believes that technical infrastructure exists to support } \\
\text { use of the system. This support can be linked to the availability of } \\
\text { necessary resources, the knowledge required to use the AVs, and } \\
\text { the compatibility of the system with other technologies currently } \\
\text { being used. Moreover, the support could also be the existence of a } \\
\text { service for assistance with system difficulties or system failure. } \\
\text { The influence of facilitating conditions on behavioural intention } \\
\text { will be mo derated by age and experience, such that the effect will } \\
\text { be stronger for older users, particularly with increasing experience. } \\
\text { Thus we propose that facilitating conditions will not have a } \\
\text { significant influence on behavioural intention }\end{array}$ \\
\hline
\end{tabular}


Table 1. (continued)

\begin{tabular}{|c|c|}
\hline Determinates/constructs & Description \\
\hline Habit $(\mathrm{H})$ & $\begin{array}{l}\text { The empirical findings about the role of habit in technology use } \\
\text { have delineated different underlying processes by which it } \\
\text { influences technology use. Related to the operationalization of } \\
\text { habit as prior use, Kim and Malhotra (2005) found that prior use } \\
\text { was a strong predictor of future technology use. Habit is the extent } \\
\text { that individuals tend to execute behaviours automatically [54], The } \\
\text { work in [12] discovered that habit directly and indirectly effects } \\
\text { Behavioural Intention to use technology. It was found that } \\
\text { increased experience in usage lead to habitual technology use. } \\
\text { Given that there are detractors to the operationalization of habit as } \\
\text { prior use [16]. some work, such as that of [54] has embraced a } \\
\text { survey and perception-based approach to the measurement of } \\
\text { habit. Such an operationalization of habit has been shown to have } \\
\text { a direct effect on technology use over and above the effect of } \\
\text { intention and also to moderate the effect of intention on } \\
\text { technology use such that intention is less important with } \\
\text { increasing habit [54] }\end{array}$ \\
\hline Cultural Influence (CI) & $\begin{array}{l}\text { Culture can be defined as what distinguishes the human element in } \\
\text { social life from what is simply biologically driven. It refers to all } \\
\text { of the beliefs, customs, ideas, behaviours, and traditions of a } \\
\text { particular society that are passed through generations. It is also } \\
\text { transmitted to people through language as well as through the } \\
\text { modeling of behaviour, and it defines which traits and behaviors } \\
\text { are considered important, desirable, or undesirable. For example, } \\
\text { there is no official law that bans women from driving but deeply } \\
\text { held religious beliefs prohibit it, with Saudi clerics arguing that } \\
\text { female drivers "undermine social values". Where Autonomous } \\
\text { vehicle adoption may be influenced by culture, the influence of } \\
\text { culture on behavioural intention will be moderated by gender }\end{array}$ \\
\hline $\begin{array}{l}\text { Behavioural Intention } \\
\text { (BI) }\end{array}$ & $\begin{array}{l}\text { Behavioural intention is defined as an individual's intention to } \\
\text { perform a given act which can predict corresponding behaviours } \\
\text { when an individual acts voluntarily. Besides that, behavioural } \\
\text { intention is the subjective probability of carrying out behaviour } \\
\text { and also the cause of certain usage behaviour [55], Thus, } \\
\text { intentions show the motivational factors that influence behaviour } \\
\text { and are indicators of how hard people are willing to try and the } \\
\text { effort they put in to engage in a behaviour. Also, it was found that } \\
\text { behavioural intention is to be the main factor of individual mobile } \\
\text { services usage and that usage intentions are rational indicators of } \\
\text { future system use }\end{array}$ \\
\hline Use Behaviour (UB) & $\begin{array}{l}\text { Use behaviour is used to measure the actual acceptance and } \\
\text { adoption of technologies or the new information systems being } \\
\text { investigated }\end{array}$ \\
\hline
\end{tabular}




\subsection{Proposed Research Model}

\section{Hypothesis Development}

H1: Performance Expectancy will be positively related to behavioural intention of using autonomous vehicles

H2: Effort Expectancy will be positively related to behavioural intention of using autonomous vehicles

H3: Social Influence will be positively related to behavioural intention of using autonomous vehicles

H4: Hedonic Motivation will be positively related to behavioural intention of using autonomous vehicles

H5: Price Value will have a significant influence on behavioural intention of using autonomous vehicles

H6: Facilitating conditions will be positively related to behavioural intention of using autonomous vehicles

H7: Habit will be positively related to behavioural intention of using autonomous vehicles

H8: Cultural Influence will have a significant influence on behavioural intention of using autonomous vehicles

H9: Moderating factors such as age, gender, experience and socioeconomic status will have an influence on the determinants of Behavioral Intention

\section{Conclusion and Future Work}

We advance the view that a more complete understanding of the actors influencing technology acceptance and adoption is necessary. These actants could be both human and non-human. Cultural influence was identified as a new construct and social class was identified as a new moderating factor obtained when combining existing technology acceptance model (TAM) to the unified theory of acceptance and use of technology (UTAUT2) and the Actor-network Theory. Focusing on the context of autonomous vehicles, we derived a set of hypotheses that linked factors related to the sociological, economic and psychological aspects. The proposed UTAUT2 - ANT has wider validity. The model can be applied, with due adjustments, to other contexts where consumers take charge of their decision-making such as for emerging technologies and other disruptive technologies. This study has some limitations that can be addressed by future research. First, we constructed the model based on detailed interviews with academics from various disciplines and surveys of potential users of self-driving cars, and on existing empirical findings and theoretical arguments in the literature across computer science, psychology and sociology. However, we did not empirically test the model. This limitation can be addressed in future research. Second, whilst we derived a set of 9 hypotheses, not all would be equally important in a specific 
setting. In addition, we may have ignored some moderating and mediating effects related to the considered variables. Future work can focus on both establishing the situation-specific nature of the proposed effects and on deriving more sophisticated hypotheses that incorporate moderating and mediating effects. We hope that this paper provides a foundation for the further exploration and understanding of technology adoption and usage jointly from social, economic, and psychological perspectives.

\section{References}

1. Venkatesh, V., Morris, M.G., Davis, G.B., Davis, F.D.: User acceptance of information technology: toward a unified view. MIS Q. 27(3), 425-478 (2003)

2. ERTRAC. Automated Driving Roadmap: Status 3rd Draft for public consultation (2015)

3. Wei, J., et al.: Towards a viable autonomous driving research platform. In: IV Intelligent Vehicles Symposium (2013)

4. Kuderer, M., Gulati, S., Burgard, W.: Learning driving styles for autonomous vehicles from demonstration. In: IEEE International Conference on Robotics \& Automation (ICRA), Seattle (2015)

5. Cowan Schwartz, R.: More Work for Mother: The Ironies of Household Technology from the Open Hearth to the Microwave. Basic Books, New York (1983)

6. Norman, D.: The Design of Everyday Things. Doubleday, New York (1990)

7. Lyytinen, K., Rose, G.: Disruptive information system innovation: the case of internet computing. Inf. Syst. J. 13, 301-330 (2003)

8. Lyytinen, K., Rose, G.: The disruptive nature of it innovations: the case of internet computing in systems development organizations. MIS Q. 27(4), 557-595 (2003b)

9. Christensen, C.: The Innovator's Dilemma: When New Technologies Cause Great Firms to Fail. Harvard Business School Press, Cambridge (1997)

10. Seba, T.: Clean Disruption of Energy and Transportation. Milton Keynes (2014)

11. Venkatesh, V., Davis, F.D.: A theoretical extension of the technology acceptance model: four longitudinal field studies. Manage. Sci. 46(2), 186-204 (2000)

12. Venkatesh, V., Thong, J.Y.L., Xu, X.: Consumer acceptance and use of information technology: extending the unified theory of acceptance and use of technology. MIS Q. 36(1), 157-178 (2012)

13. Fishbein, M., Ajzen, I.: Belief, Attitude, Intention and Behavior: An Introduction to Theory and Research. Addison-Wesley, Reading (1975)

14. Davis, F.D., Bagozzi, R., Warshaw, P.: User acceptance of computer technology: a comparison of two theoretical models. Manage. Sci. 35, 982-1003 (1989). doi:10.1287/ mnsc.35.8.982

15. Davis, F., Bagozzi, R., Warshaw, P.: Extrinsic and intrinsic motivation to use computers in the workplace. J. Appl. Soc. Psychol. 22(14), 1111-1132 (1992)

16. Ajzen, I.: Perceived behavioral control, self-efficacy, locus of control, and the theory of planned behavior. J. Appl. Soc. Psychol. 32, 665-683 (2002)

17. Taylor, S., Todd, P.: Assessing it usage: the role of prior experience. MIS Q. 19(4), 561-570 (1995a)

18. Taylor, S., Todd, P.: Understanding information technology usage: a test of competing models. Inf. Syst. Res. 6, 144-176 (1995b)

19. Thompson, R.L., Higgins, C.A., Howell, J.M.: Personal computing: toward a conceptual model of utilization. MIS Q. 15(1), 125-143 (1991) 
20. Moore, G.C., Benbasat, I.: Development of an instrument to measure the perceptions of adopting an information technology innovation. Inf. Syst. Res. 2(3), 192-222 (1991)

21. Compeau, D.R., Higgins, C.A., Huff, S.: Social cognitive theory and individual reactions to computing technology: a longitudinal study. MIS Q. 23(2), 145-158 (1999)

22. San Martin, H., Herrero, A.: Influence of the user's psychological factors on the online purchase intention in rural tourism: integrating innovativeness to the UTAUT framework. Tourism Manage. 33(2), 341-350 (2012). doi:10.1016/j.tourman.2011.04.003

23. Gruzd, A., Staves, K., Wilk, A.: Connected scholars: examining the role of social media in research practices of faculty using the UTAUT model. Comput. Hum. Behav. 28, 2340-2350 (2012)

24. World Health Organization, World report on road traffic injury prevention, Geneva (2004). http://whqlibdoc.who.int/publications/2004/9241562609.pdf?ua=1. Accessed 26 June 2015

25. Garvin, A.D., Roberto, A.M.: Change through persuasion. Harvard Bus. Rev. 83, 104-112 (2005)

26. KPMG. Connected and Autonomous Vehicles - The Economic opportunity, s.l., SMMT Driving the motor industry (2015)

27. Stanley, M.: Autonomous Cars: Self-Driving the New Auto Industry Paradigm, s.l., Morgan Stanley Blue paper (2013)

28. Hoogendoorn, R., et al.: Towards safe and efficient driving through vehicle automation: the Dutch automated vehicle initiative (2013)

29. Jóhannesson, G.T.: Tourism translations, actor-network theory and tourism research. Tourist Stud. 5(2), 133-150 (2005)

30. Rhodes, J.: Using actor-network theory to trace an ICT (telecenter) implementation trajectory in an African women's micro-enterprise development organization. USC Annenberg School for Communication 5(3), pp. 1-20 (2009)

31. Alcadipani, R., Hassard, J.: Actor-network theory, organizations and critique: towards a politics of organizing. Organization 17(4), 419-435 (2010)

32. Arnaboldi, M., Spiller, N.: Actor-network theory and stakeholder collaboration: the case of cultural districts. Tourism Manage. 32(3), 641-654 (2011)

33. Cohen, E., Cohen, S.A.: Current sociological theories and issues in tourism. Annals of Tourism Research (2012). http://dx.doi.org/10.1016/j.annals.2012.07.009

34. Latour, B.: Reassembling the Social: An Introduction to Actornetwork-Theory. Clarendon Lectures in Management Studies. Oxford University Press, New York (2005)

35. Latour, B.: The Powers of association. In: Law, J. (ed) Power, action and belief: A new Sociology of Knowledge? Sociological Review Monograph, vol. 32, pp. 264-280. Routledge \& Kegan Paul, London (1986)

36. Latour, B.: The prince for machines as well as for machinations. In: Elliott, B. (ed) Technology and Social Process. Edinburgh University Press, Edinburgh, pp. 20-43 (1988b)

37. Latour, B.: Technology is society made durable. In: Law, J. (ed.) A Sociology of Monsters. Essays on Power, Technology and Domination, pp. 103-131. Routledge, London (1991)

38. Latour, B.: We Have Never Been Modern. Harvester Wheatsheaf, Hemel Hempstead (1993)

39. Latour, B.: On actor-network theory - a few clarifications. Soziale Welt-Zeitschrift fur Sozialwissenschaftliche forschung und praxis 47(4), 369 (1996)

40. Latour, B., Woolgar, S.: Laboratory Life, The Social Construction of Scientific Facts, New Edition edn. Princeton University Press, Princeton (1986)

41. Garrety, K.: Actor Network Theory. In: Hasan, H. (ed.) Being Practical with Theory: A Window into Business Research. University of Wollongong, Wollongong (2014) 
42. Callon, M.: Some elements of a sociology of translation: domestication of the scallops and the fishermen of St Brieuc bay'. In: Law, J. (ed) Power, Action \& Belief: A New Sociology of Knowledge? Routledge \& Kegan Paul, London, pp. 196-229 (1986b)

43. Dolwick, J.S.: The social and beyond: introducing actor-network theory. J. Marit. Archaeol. 4(1), 21-49 (2009)

44. Law, J.: Making a mess with method (2003). http://www.lancs.ac.uk/fass/sociology/papers/ law-making-a-mess-with-method.pdf

45. Tatnall, A., Burgess, S.: Using actor-network theory to research the implementation of a B-B portal for regional SMEs in Melbourne, Australia. In: 15th Bled Electronic Commerce Conference, Slovenia, 17-19 June (2002)

46. Tatnall, A., Gilding, A.: Actor-network theory and information systems research. In: Proceedings of the 10th Australasian Conference on Information Systems (ACIS), Wellington, Victoria University of Wellington (1999)

47. Van Der Duim, R., Henkens, R.: Wetlands, poverty reduction and sustainable tourism development, opportunities and constraints, Wageningen, the Netherlands, Wetlands International (2007)

48. Paget, E., Dimanche, F., Mounet, J.P.: A tourism innovation case: an actor-network approach. Ann. Tourism Res. 37(3), 828-847 (2010)

49. Ritzer-Encyclopedia (2004). www.sagepub.com/upm-data/5222_Ritzer_Entries_beginning_ with_.A_\%5B1\%5D.pdf. Accessed 2 Nov 2015

50. Rodger, K.J.: Wildlife tourism and the natural sciences: bringing them together. Ph.D. Thesis, School of Environmental Science, Division of Science and Engineering, Murdoch University, Perth, Western Australia (2007)

51. McLean, C., Hassard, J.: Symmetrical absence/symmetrical absurdity: critical notes on the production of actor-network accounts. J. Manage. Stud. 41(3), 493-519 (2004). doi:10.1111/ j.1467-6486.2004.00442.x. Publication link:a2df43f6-178d-4c31-88e5-f61c0ebd2d14

52. Burgess, J., Clark, J., Harrison, C.M.: Knowledge in action: an actor network analysis of a wetland agri-environment scheme. Ecol. Econ. 35(1), 119-132 (2000)

53. Dodds, W.B., Monroe, K.B., Grewal, D.: Effect of price, brand and store information on buyers' product evaluations. J. Market. Res. 28(3), 307-319 (1991)

54. Limayem, M., Hirt, S.G., Cheung, C.M.K.: How habit limits the predictive power of intention: the case of information systems continuance. MIS Q. 31(4), 705-737 (2007)

55. Yi, M.Y., Jackson, J.D., Park, J.S., Probst, J.C.: Understanding information technology acceptance by individual professionals: toward an integrative view. Inf. Manage. 43, 350363 (2006)

56. Connor, M.: Automobile sensors may usher in self-driving cars. Ed. Margery Connor. N.p., 26 May 2011. http://www.edn.com/design/automotive/4368069/Automobile-sensors-mayusher-in-self-driving-cars. Accessed 09 Sep 2016

57. Olarte, O.: Human error accounts for $90 \%$ of road accidents. driver risk management solutions (2011). http://www.alertdriving.com/home/fleet-alert-magazine/international/ human-error-accounts-90-road-accidents/. Accessed 09 Sep 2016 